\title{
ANALISIS PULSE MOTOR SERVO SEBAGAI PENGGERAK UTAMA LENGAN ROBOT BERJARI BERBASIS MIKROKONTROLER
}

\author{
Selamat Muslimin \\ Politeknik Negeri Sriwijaya \\ Email : selamet_muslimin@polsri.ac.id
}

\begin{abstract}
Lengan robot berjari telah banyak digunakan pada industri maupun dalam bidang pendidikan. Perancangan lengan robot berjari sebelumnya dibahas dalam permasalahan flex sensor. Robot dibagi atas dua bagian, bagian pengendali pada lengan manusia (transmitter) dan lengan robot (reciever). Lengan robot berjari ini berbasis mikrokontroler dengan menggunakan ATMega 32A pada pengendali dan ATTiny 2313. Robot menggunakan media wireless yaitu KYL 1020U. Dibutuhkan keseimbangan perancangan antara aspek mekanik dan elektronik untuk menghasilkan kinerja lengan robot berjari yang maksimal. Artikel ini membahas lebar pulsa motor servo bahu, lengan, siku bawah dan siku atas. Sudut putar motor servo ketika diberi beban dan tidak beroperasi adalah $0^{\circ}$ sampai dengan $160^{\circ}$ dengan rata-rata lebar pulsa 1,2 dan 1,7. Pada saat diberi beban dan beroperasi, sudut putar servo dan rata-rata lebar pulsa tidak berubah. Ini menunjukkan bahwa servo yang digunakan pada lengan robot sangat stabil. Nilai arus yang mengalir pada lengan robot berjari akan naik sesaat dari 6,7 mA menjadi $7 \mathrm{~mA}$ ketika motor servo bergerak (berputar), namun nilai arus tersebut akan kembali ke nilai awal (6,7 mA) ketika motor servo berhenti bergerak (berputar).
\end{abstract}

Kata kunci : flex sensor, resistivitas, lengan robot berjari, mikrokontroler, KYL $1020 U$

\section{PENDAHULUAN}

Lengan robot berjari merupakan teknologi robot yang dapat bergerak mengikuti gerakan lengan. Dalam pembuatan lengan robot berjari ini diperlukan beberapa motor servo sebagai penggerak lengan mau pun jari robot. Untuk menggerakkan motor servo diperlukan modul servo controller untuk mengatur gerakan lengan robot agar dapat bergerak secara selaras dan seimbang. Untuk mengendalikan servo controller, dalam lengan robot digunakan suatu pengendali yang disebut mikrokontroler, sehingga sistem gerak dari lengan robot menjadi otomatis. Motor servo adalah sebuah motor DC yang dilengkapi rangkaian kendali yang terintegrasi dengan motor. Motor servo pada dasarnya adalah motor DC magnet permanen dengan kualifikasi khusus yang sesuai dengan aplikasi servoing di dalam teknik control (Pitowarno, 2006). Motor servo merupakan salah satu jenis motor DC yang sudah sangat familiar dalam ilmu robotika karena banyak robot yang menggunakan motor servo sebagai aktuator robot. Motor servo memiliki karakteristik yang berbeda dengan motor DC biasa, yaitu dalam hal pengoperasiannya yang harus menggunakan pulsa digital (Pulse Width Modulation) dimana lebar dari pulsa digital tersebut sangat mempengaruhi arah putaran motor servo serta besar sudut yang akan dibentuk oleh putaran motor servo.
Beberapa tipe motor servo yang dijual bersama dengan paket rangkaian driver-nya telah memiliki rangkaian kontrol kecepatan yang menyatu di dalamnya. Putaran motor tidak lagi berdasarkan tegangan supply ke motor, namun berdasarkan tegangan input khusus yang berfungsi sebagai referensi kecepatan output. Motor servo pada dasarnya mempunyai sistem close loop sehingga dapat mempertahankan horn pada posisinya. Motor servo terdiri dari sebuah motor DC kecil, sistem kombinasi gear yang berfungsi mengatur kecepatan motor DC, sebuah potensiometer, dan sebuah rangkaian controller. Pada umumnya motor servo memerlukan sinyal input dalambentuk PWM (Pulse Width Modulation) dengan jangkauan gerakan poros outputnya berkisar antara $-120^{\circ}$ - $120^{\circ}$ (Pitowarno, 2006). Motor servo akan bekerja secara baik jika pada bagian pin kontrolnya diberikan pulsa PWM dengan frekuensi $50 \mathrm{~Hz}$, dimana pada saat sinyal dengan frekuensi $50 \mathrm{~Hz}$ tersebut dicapai pada kondisi Ton Duty Cycle $1.5 \mathrm{~ms}$, maka rotor dari motor akan berhenti tepat di tengahtengah (sudut $90^{\circ}$ ). Semakin lebar pulsa high (Ton) maka akan semakin besar gerakan sumbu ke arah yang berlawanan jarum jam. Sebaliknya, semakin kecil pulsa high (Ton) maka akan semakin besar gerakan sumbu ke arah yang searah dengan jarum jam. Pada gambar 1 ditunjukkan sudut yang dibentuk 
oleh motor servo berdasarkan lebar pulsa yang diberikan.

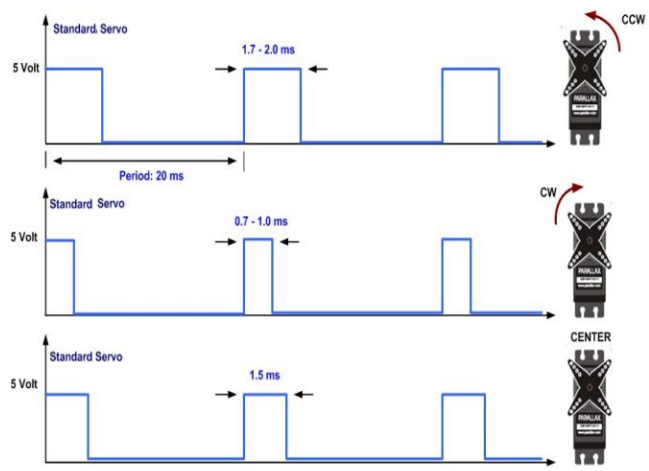

Gambar 1. Pengaruh pemberian pulsa terhadap sudut motor servo

\section{Jenis Motor Servo}

Secara umum motor servo terdiri atas dua jenis, yaitu Motor Servo Standar $180^{\circ}$ dan Motor Servo Continuous (Pitowarno, 2006).

1. Motor Servo Standar $180^{\circ}$ adalah motor servo yang mampu bergerak dua arah (CW dan $\mathrm{CCW}$ ) dengan defleksi masingmasing sudut mencapai $90^{\circ}$ sehingga total defleksi sudut dari kanan - tengah kiri adalah $180^{\circ}$.

2. Motor Servo Continuous adalah motor servo yang mampu bergerak dua arah $(\mathrm{CW}$ dan CCW) tanpa batasan defleksi sudut putar sehingga dapat bergerak sampai satu putaran penuh sebesar $360^{\circ}$.

Motor servo merupakan suatu motor DC yang dapat digerakkan membentuk sudut-sudut tertentu dengan memberikan pulsa selebar 0,6 1,4 ms untuk logika high dan pulsa selebar 17,619,4 ms untuk logika low (20 ms untuk lebar pulsa selama 1 perioda) sebanyak 50 kali dalam 1 detik. Selama pulsa logika low untuk motor servo 1 berlangsung, itu dapat dimanfaatkan untuk memberikan pulsa logika high untuk motor servo selanjutnya. Gambar 2 menunjukkan pulsa yang dihasilkan untuk mengontrol motor servo.

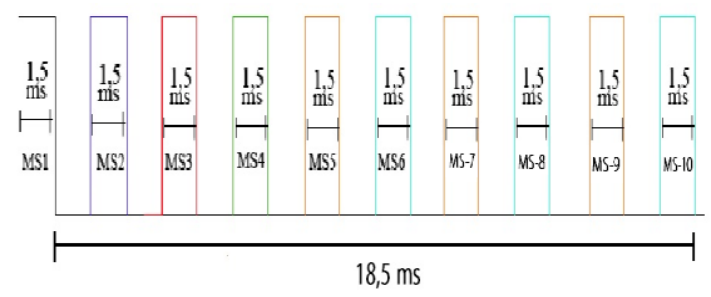

Gambar 2. Pengaruh pemberian pulsa terhadap posisi motor servo.

\section{Potensiometer}

Robot ini membutuhkan sebuah sensor sebagai pengendali pada lengan robot. Sensor ini dipasang pada persendian tangan manusia dengan bantuan tambahan mechanical controller yang fleksibel jika dipakai pada lengan dan tangan manusia. Sensor yang cocok yang digunakan pada persendian lengan manusia ialah potensiometer, sebagai sensor posisi. Potensiometer adalah sensor analog yang paling sederhana namun sangat berguna untuk mendeteksi posisi putaran, misalnya kedudukan sudut aktuator berdasarkan nilai resistansi pada putaran porosnya. Untuk mendapatkan hasil yang linier, potensiometer yang digunakan berjenis Potensiometer Linier.

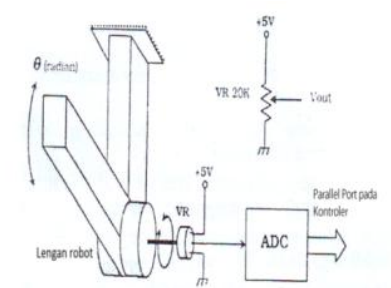

Gambar 3. Potensiometer sebagai sensor posisi

\section{Mikrokontroler}

Mikrokontroler pada pembuatan lengan robot ini memiliki peran yang sangat penting karena digunakan sebagai komponen utama, yaitu sebagai tempat pengolahan program yang dibuat untuk menggerakkan lengan robot seperti halnya otak sebagai pusat perintah untuk kerja semua organ pada manusia. Pada pembuatan lengan robot ini digunakan mikrokontroler jenis AVR karena memiliki keunggulan dari segi kemampuan dan juga harga..

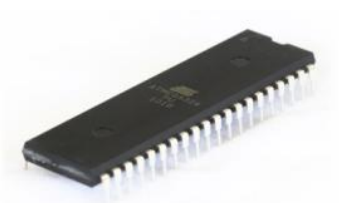

Gambar 4. Mikrokontroler ATMega 32

\section{KYL 1020u}

KYL 1020u digunakan sebagai pengirim data dari pengendali ke lengan robot. Caranya yaitu dengan menghubungkan $\mathrm{Rx}$ dan $\mathrm{Tx}$ mikrokontroler bagian pengendali dengan modul KYL 1020u pertama sebagai transmitter. Selanjunya KYL 1020u kedua dihubungkan dengan $\mathrm{Rx}$ dan $\mathrm{Tx}$ mikrokontroler lengan robot sebagai reciever. Gambar 4 berikut ini menunjukkan koneksi KYL 1020u transmitter dan receiver dengan perangkat

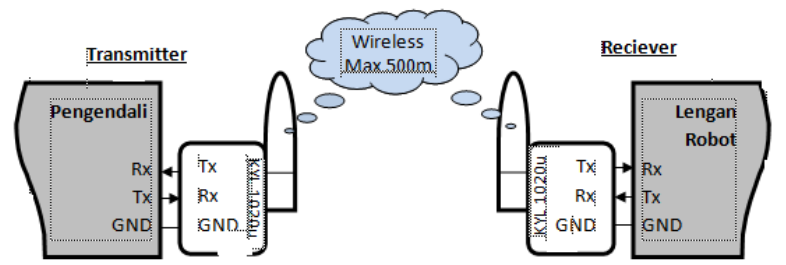

Gambar 4. Koneksi KYL 1020U 


\section{METODE}

Alur penelitian mengikuti metode kerja sistem kontrol, dimana mekanisme lengan robot dirakit mengikuti desain yang ada. Kemudian menyusun rangkaian pengendali mengikuti aliran logika sebagaimana tampak pada diagram alir pada Gambar 5. Dari gambar diagram alir tampak proses pengolahan data mulai dari data input yang berasal dari rangkaian pembagi tegangan dan potensiometer. Sinyal analog dari sensor masuk ke dalam mikrokontroler ATMega 32 dan dikonversikan ke sinyal digital (ADC). Sinyal digital akan dikirim (dimodulasikan) menjadi sinyal wireless oleh KYL 1020U bagian transmitter. Sinyal wireless tersebut akan diterima oleh KYL 1020U bagian reciever dan diteruskan ke dalam mikrokontroler ATTiny 2313 hingga dihasilkan output berupa pulsa digital yang akan menggerakkan motor servo. Program yang digunakan dalam pembuatan Lengan Robot Pengikut Gerak Lengan Manusia ini berbasis bahasa pemrograman Turbo $\mathrm{C}++$. Setelah sistem siap seluruhnya, baru dilakukan pengujian perubahan lebar pulsa dan sudut dalam kondisi berbeban dan tanpa beban.

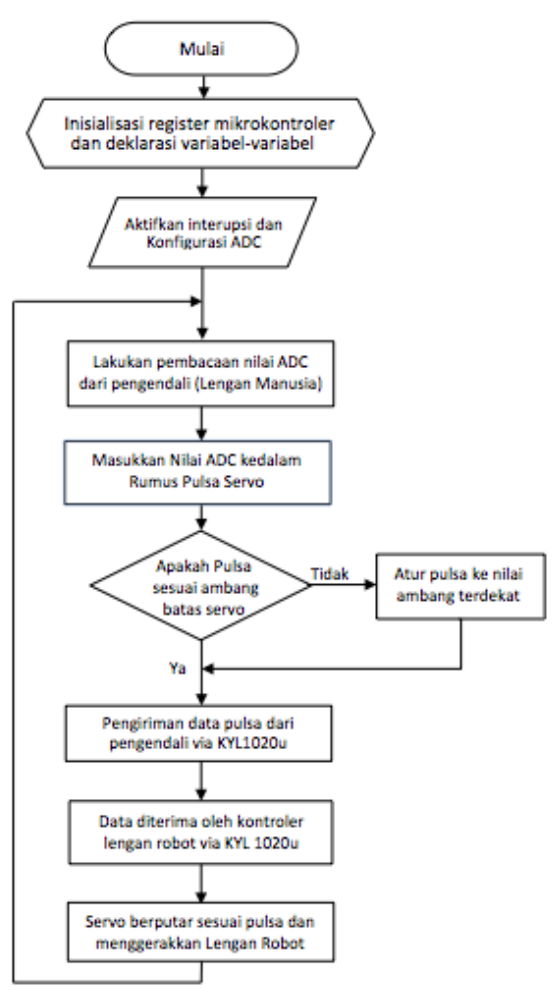

Gambar 5. Diagram alir pengendalian lengan robot

\section{HASIL DAN PEMBAHASAN}

Rangkaian pengendali dan mekanisme lengan robot ditunjukkan pada Gambar 6 dan 7 berikut ini

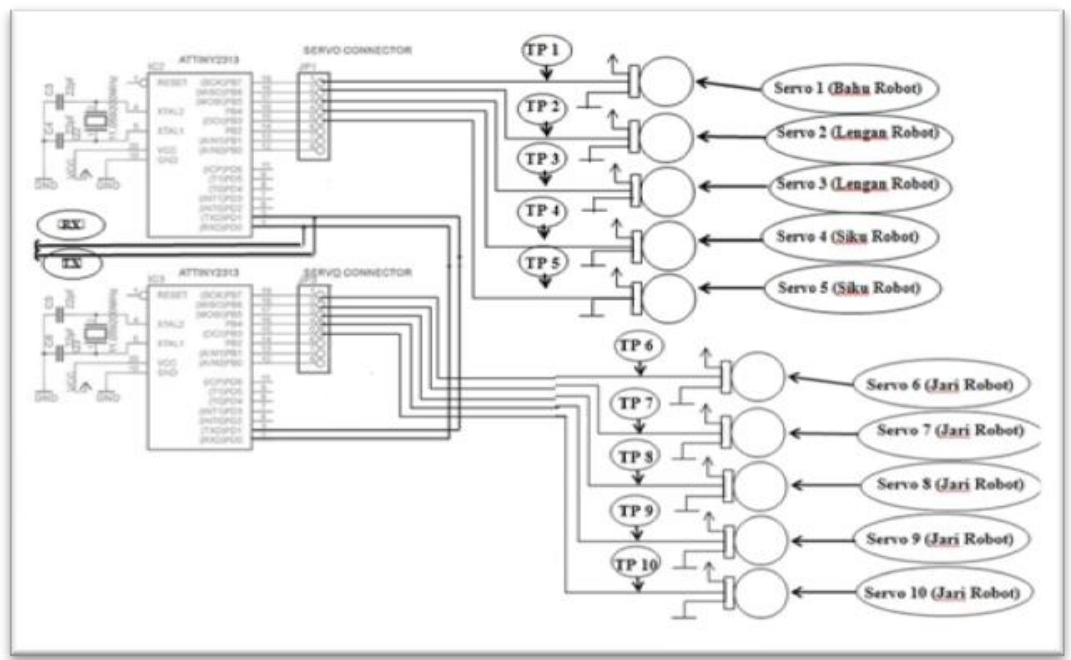

Gambar 6. Rangkaian Pengendalian Lengan Robot 


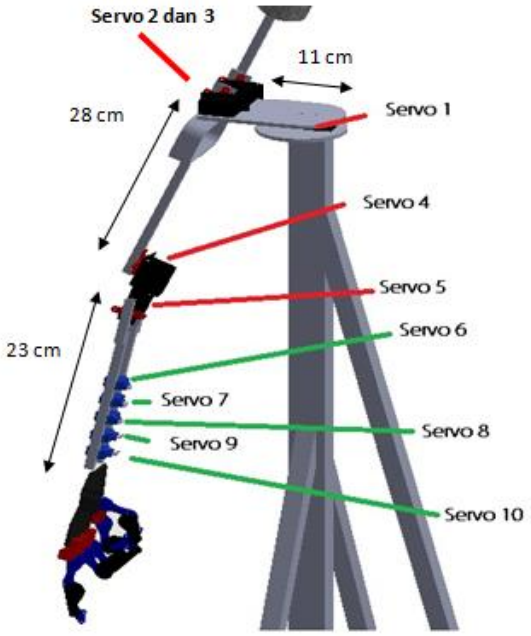

(a) Receiver

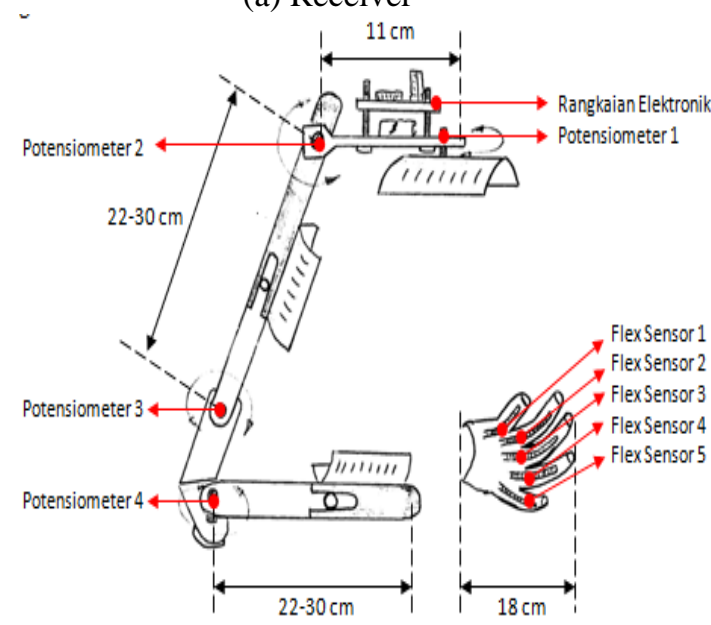

(b) Transmitter

Gambar 7. Pengendali lengan robot receiver dan transmitter

\section{Analisa Program \\ Berikut ini adalah penjelasan singkat tentang program di dalamATTiny 2313:}

\section{\#define SERVO_PORT PORTB \#define SERVO_DDR DDRB}

// Upto 8 servos (since pulses are generated in // sequence + only one port is used). \#define N_SERVOS 8

Program ini menandakan bahwa port IC mikrokontroler yang digunakan untuk motor servo pada ATTiny 2313 adalah port $B$.

// Servo times (this is Futaba timing).

\#define SERVO_MIN 600//920// $\mathrm{s}$

\#define SERVO_MAX 2400//2120 // $\mu$ s

\#define SERVO_MID (SERVO_MIN + SERVO_MAX) / 2

Program ini menentukan besar minimum dan maksimum pulsa yang diberikan untuk motor servo. Untuk motor servo dalam keadaan netral maka besar pulsa maksimum ditambahkan dengan besar pulsa minimum kemudian dibagi dua.

// Time between servo pulses.

\#define SERVO_FRAME $20000 / / \mu \mathrm{s}(50 \mathrm{~Hz}$

Program ini menandakan panjang pulsa digital yang akan diberikan oleh mikrokontroler ATTiny 2313 untuk motor servo, yaitu sepanjang $20 \mathrm{~ms}$ (milidetik).

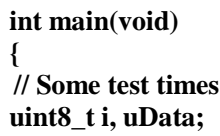

Program ini adalah program utama yang akan menggerakkan motor servo, ketika lengan robot baru dihidupkan maka mikrokontroler ATTiny 2313 akan memberikan lebar pulsa digital yang sama ke setiap motor servo yaitu sebesar $1,5 \mathrm{~ms}$, namun ketika lengan robot mulai dioperasikan maka pulsa digital yang diberikan untuk setiap motor servo akan berubah sesuai dengan data digital dari pengendali lengan robot

\section{Hasil Pengujian}

Hasil pengujian kinerja lengan robot ditunjukkan pada Tabel 1-3. Dengan mengacu pada data table-tabel tersebut tampak bahwa lebar pulsa dalam kondisi berbeban dan tanpa beban tidak jauh berbeda. Hal ini menunjukkan bahwa 
mekanisme lengan robot yang didesain sudah stabil.

Tabel 1. Motor servo pada keadaan awal

\begin{tabular}{|c|c|c|c|c|}
\hline$\overline{\text { Motor:Servoa }}$ & $\overline{\text { Vin }(\text { Volt }) a}$ & Iin (Ma) $a$ & LebarPulsa (Ms)a & SudutPutara \\
\hline Servo-1.(Bahu)a & 5,020 & $0,28 a$ & 1,50 & $90^{\circ}$ \\
\hline Servo $2 \cdot \& \cdot 3 \cdot($ Lengan) & 5,020 & 0,28 & 1,50 & $90^{\circ} \infty$ \\
\hline Servo-4.(SikuAtas)a & 5,020 & $0,28 a$ & 1,50 & $90^{\circ} \alpha$ \\
\hline Servo $\$$ (SikuBawah)a & $5,02 \approx$ & 0,29 a & 1,50 & $90^{\circ} \infty$ \\
\hline
\end{tabular}

Tabel 2. Motor servo diberi beban dan tidak beroperasi

\begin{tabular}{|c|c|c|c|c|c|c|c|c|c|}
\hline SudutPutara & $0^{\circ} \alpha$ & $45^{\circ} \alpha$ & $75^{\circ} \alpha$ & $90^{\circ} a$ & $115^{\circ} \mathrm{d}$ & $125^{\circ} \alpha$ & $135^{\circ} \alpha$ & $160^{\circ} \alpha$ & Posisio \\
\hline$\overline{\text { LebarPulsa (Ms)a }}$ & -2 & $-\sqrt{-a}$ & $1,4 a$ & $1,5 a$ & 1,70 & -2 & $-\infty$ & $-a$ & Servo Bahuo \\
\hline LebarPulsa (Ms)a & $-\infty$ & $1,4 \alpha$ & a & $1,5 x$ & a & $-\infty$ & $1,7 \alpha$ & $-\infty$ & Servo-Lengan $\alpha$ \\
\hline LebarPulsa (Ms)a & 1,20 & 1,40 & a & 1,50 & a & $-\infty$ & $-\infty$ & $-\infty$ & Servo-SikuBawaho \\
\hline LebarPulsa (Ms)a & $-\infty$ & 0,60 & a & $1,2 \alpha$ & a & $1,4 a$ & $-\alpha$ & 1,70 & Servo-SikuAtas \\
\hline
\end{tabular}

Tabel 3. Motor servo diberi beban dan beroperasi

\begin{tabular}{|c|c|c|c|c|c|c|c|c|c|}
\hline SudutPutara & $0 \%$ & $45^{\circ} a$ & $75^{\circ} a$ & $90^{\circ} \mathrm{a}$ & $115^{\circ} \mathrm{x}$ & $125^{\circ} \mathrm{a}$ & $135^{\circ} a$ & $160^{\circ} a$ & Posisia \\
\hline LebarPulsa (Ms)a & $-\infty$ & $-\infty$ & $1,4 \infty$ & 1,50 & $1,7 \%$ & $-\sqrt{x}$ & $-\infty$ & $-\bar{a}$ & Servo Bahuq \\
\hline LebarPulsa (Ms)a & $-\infty$ & 1,40 & a & $1,5 \infty$ & a & $-a$ & $1,7 \alpha$ & -2 & Servo-Lengan \\
\hline LebarPulsa (Ms)a & 1,20 & 1,40 & a & 1,5 & a & $-\infty$ & -2 & $-\infty$ & Servo-SikuBawaho: \\
\hline LebarPulsa (Ms)a & $-\infty$ & 0,60 & a & 1,20 & a & $1,4 \infty$ & - & $1,7 x$ & Servo-SikuAtas \\
\hline
\end{tabular}

Data Diambil Di Lab. MekatronikaPolsri

\section{KESIMPULAN}

Keanekaan jenis komponen kontroler lengan robot dan variasi desain lengan pada dasarnya membutuhkan kestabilan kondisi kerja dengan simpangan kondisi dari keadaan awal yang tidak terlalu besar. Kemampuan kembali ke posisi semula sangat penting. Desain mekanik, komponen kontroler, dan pemrograman pengendalian yang dipilih dalam penelitian ini menunjukkan kestabilan kerja yang dimaksud sehingga layak untuk dioperasikan.

\section{DAFTARPUSTAKA}

Maria V. Dan Dwi W.U. 2013. Rancang Bangun Jari Tangan Robot Pengikut Pergerakan Jari Tangan Manusia. Jurnal. Palembang: STMIK MDP.

Petruzella, Frank D. 2001.Elektronik Industri. Yogyakarta: ANDI.

Pitowarno, Endra. 2006. Robotika Desain, Kontrol, dan Kecerdasan Buatan.Yogyakarta: ANDI.

Setiawan, Iwan. 2009. Buku Ajar Sensor dan Transduser. In: Sensor dan Transduser. Faculty of Engineering, Diponegoro University

http://elib.unikom.ac.id Diakses 15 Juni 2014 Pk. $12.25 \mathrm{WIB}$

Syafril, Deny. Wijaya, Yusmar Palapa. Madona, Putri. 2013. Penghematan daya pada sensor node dengan menggunakan metode pengaturan waktu kirim data. Jurnal Teknik Elektro dan Komputer. 1(1) : 18-28 